
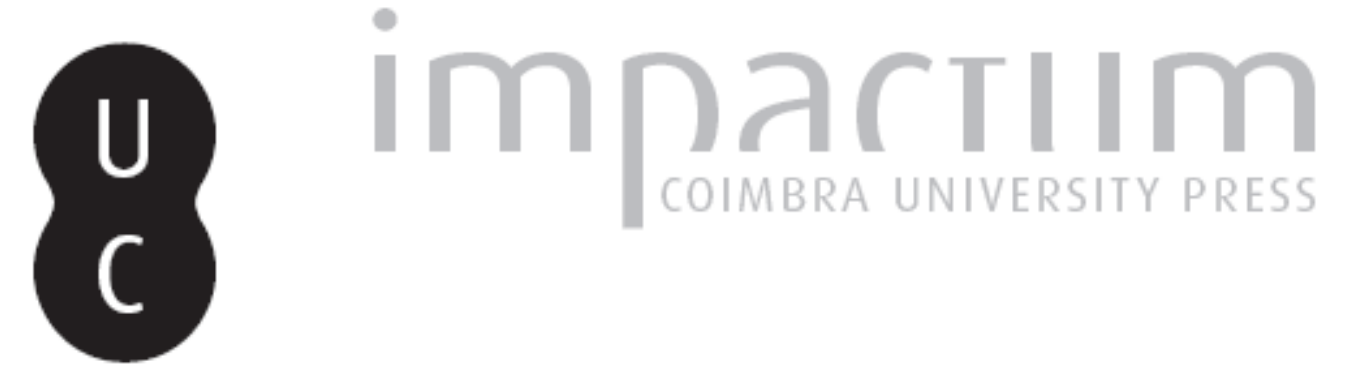

\title{
Patrimónios de Coimbra - Univer(c)idade: património e desenvolvimento?
}

Autor(es): $\quad$ Ferreira, Vítor; Santos, Norberto

Publicado por: Imprensa da Universidade de Coimbra

URL persistente:

URI:http://hdl.handle.net/10316.2/40772

DOI:

DOI:https://doi.org/10.14195/0871-1623_35_3

Accessed : $\quad$ 26-Apr-2023 09:54:46

A navegação consulta e descarregamento dos títulos inseridos nas Bibliotecas Digitais UC Digitalis, UC Pombalina e UC Impactum, pressupõem a aceitação plena e sem reservas dos Termos e Condições de Uso destas Bibliotecas Digitais, disponíveis em https://digitalis.uc.pt/pt-pt/termos.

Conforme exposto nos referidos Termos e Condições de Uso, o descarregamento de títulos de acesso restrito requer uma licença válida de autorização devendo o utilizador aceder ao(s) documento(s) a partir de um endereço de IP da instituição detentora da supramencionada licença.

Ao utilizador é apenas permitido o descarregamento para uso pessoal, pelo que o emprego do(s) título(s) descarregado(s) para outro fim, designadamente comercial, carece de autorização do respetivo autor ou editor da obra.

Na medida em que todas as obras da UC Digitalis se encontram protegidas pelo Código do Direito de Autor e Direitos Conexos e demais legislação aplicável, toda a cópia, parcial ou total, deste documento, nos casos em que é legalmente admitida, deverá conter ou fazer-se acompanhar por este aviso.

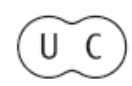




\title{
Patrimónios de Coimbra - Univer(c)idade: património e desenvolvimento? Heritages of Coimbra - Univers(c)ity: heritage and developmment?
}

\author{
Vítor Ferreira \\ Centro de Estudos de Geografia e Ordenamento do Território - CEGOT. \\ vitor.ferreira@student.fl.uc.pt

\section{Norberto Santos} \\ Departamento de Geografia e Turismo da Faculdade de Letras da Universidade de Coimbra e Centro de Estudos \\ de Geografia e Ordenamento do Território - CEGOT. \\ norgeo@ci.uc.pt
}

\section{Resumo:}

A necessidade de diferenciação dos territórios tem sido acompanhada pela afirmação e pelo reconhecimento das suas particularidades intrínsecas, contexto em que as universidades e os seus bens patrimoniais ganhar um foco específico. Este destaque é devido a uma extensão sucessiva da noção de Património Cultural, ou o que alguns autores designam como uma "tripla extensão conceptual”, simultaneamente tipológica, cronológica e geográfica.

Pretende-se com este artigo entender como a classificação recente da "Universidade, Alta e Sofia" como Património Mundial, em Coimbra, poderá ser promotor do desenvolvimento económico da região centro de Portugal e da cidade de Coimbra. A função primária daquele ativo patrimonial ainda é a educação, havendo uma pressão acrescida sobre a sua gestão para se constituir como elemento central do ressurgimento da cidade como um destino cultural e turístico.

Questiona-se que futuro tem o Património Cultural da cidade se a intenção é preservar a herança material e imaterial, e como esta ação convive com a visão das novas exigências recreativas e turísticas, considerados alicerces de um desenvolvimento futuro. Procura-se ver como diferentes políticas, atitudes e visões influenciam e determinam a capacidade de identificar e cativar os valores e as funções que derivam desses bens patrimoniais.

Palavras Chave: Património Cultural. Coimbra. Desenvolvimento. Estratégias. Políticas.

\section{Abstract:}

The need for territorial differentiation has been stated by the recognition of its intrinsic particularities where universities and its heritage assets gain a specific focus. This prominence is due to a successive extension of the notion of Cultural Heritage, or what some authors consider as a "triple conceptual extension" that is typological, chronological and geographical.

It is intended with this paper to understand how the recent classification of the "University, Alta and Sofia" as world heritage could be a trigger for the economic development of the center region of Portugal and the city of Coimbra. We have to keep in mind that the primary functions of these Cultural Heritage asset is still education and that, simultaneously, there is a heightened pressure on the asset management to be a central key of the reemergence of the city as a cultural destination.

We intend to trace what kind of future has the city's Cultural Heritage as we see that there is the intention to preserve the tangible and intangible heritage but also a vision that the new recreational and tourist demands are the base of a future development. Preliminarily, is possible to conclude that Coimbra's Cultural Heritage is extremely dependent on different policies and attitudes that influence the ability to identify and activate values and functions provided by these Cultural Heritage assets, so reliant on place and society.

Keywords: Cultural Heritage. Coimbra. Development. Strategies. Policies.

\section{Introdução}

0 paradigma sociocultural em que vivemos hoje alterou profundamente o conceito de Património Cultural. Este sofreu uma evolução constante ao longo das últimas décadas, o que lhe confere uma nova centralidade no campo das ciências sociais (Borga, 2015, Bouchenaki, 2014; Heinich, 2009; Heinich, 2011; Lipovetsky e Serroy, 2010, Macdonald, 2013; Rebelo e Brito, 2014; Worthing, e Bond, 2008). A centralidade que estava no campo da preservação e da conservação do Património Cultural 
passou, fruto daquilo que alguns autores designam como a "tripla extensão do conceito", ou seja, uma extensão tipológica, cronológica e geográfica, para campos até então inexistentes (Vecco, 2010; Graham, Ashworth e Tunbridge, 2000). O Património Cultural é progressivamente encarado como uma alavanca para o progresso das comunidades que the dão origem e que o vivificam (Graham, Ashworth, e Tunbridge, 2000).

Será que os responsáveis políticos, como refere Boyer (2005, citado por Amin e Thrift, 2007), ao debruçarem-se sobre as questões culturais, as consideram como tendo pouca importância, ou influência sobre as leis básicas da economia e/ou das profundas estruturas de poder? Graham (2002) quando refere que o Património Cultural é um conhecimento que se constitui como capital cultural mas também como capital económico, indica-nos que devemos contrariar esta perspetiva. O Património Cultural alcança assim uma importância que the confere uma nova centralidade, devido a este posicionamento, mas igualmente na medida em que estamos numa época em que as ideias de espaço multi-escalar, por oposição ao tempo, constituem o paradigma dominante de análise em teoria cultural. Esta importância do espaço e das relações que ele estabelece, entre o global e o local, dá uma grande expressividade à viagem e ao reconhecimento dos lugares como destinos turísticos. É neste contexto que ganha especial significado o reconhecimento pela UNESCO de Coimbra como Património Mundial.

Este artigo pretende em primeira instância caracterizar os patrimónios existentes na unidade/ dualidade Univers(c)idade, as suas funções primárias e usos correntes. Far-se-á de seguida uma análise das principais políticas e estratégias de desenvolvimento passíveis de identificação nas orientações políticas e planos estratégicos, para de seguida as confrontar com a perceções que os diferentes 'stakeholders', com responsabilidade políticas e de gestão dos bens patrimoniais, têm das mesmas.

Este percurso será efetuado através de uma revisão da literatura e de entrevistas semiestruturadas, de forma a conhecer as possibilidades que os bens patrimoniais da cidade têm, mas igualmente registar como as políticas de promoção e salvaguarda do Património Cultural em vigor podem sustentar ou colocar em perigo as diferentes iniciativas de desenvolvimento e confrontar as mesmas como os caminhos definidos para os bens patrimoniais da cidade.

A relevância e originalidade do estudo passa pela reflexão e análise das políticas e missões emanadas dos textos legislativos e regulamentares, do seu confronto com os planos estratégicos para a cidade, sendo os mesmos, em última instância, confrontados com as perceções dos diferentes 'stakeholders'. Que possibilidades têm os bens patrimoniais que a cidade possui quando a intenção é de preservar o tangível e o intangível, mas simultaneamente vigora uma visão em que a recreação e a procura turística são as bases da política de desenvolvimento futuro?

\section{Estado do conhecimento e metodologia}

Poderá a recente classificação pela UNESCO da "Universidade, Alta e Sofia" como Património Mundial, com base no corrente contexto político e estratégias de desenvolvimento, sejam elas nacionais ou locais, constituir-se como motor de desenvolvimento económico da região centro de Portugal e da cidade de Coimbra?

A interpretação de Tuan (1974) ao falar de existência de um espírito do lugar, aliada à classificação, bem como à monumentalidade urbana, cria lugares simbólicos públicos (Tuan, 1970) tornando a cidade em criadora e agregadora de marcos territoriais, como sucede em Coimbra.

Este enquadramento é sustentado no facto de o espaço urbano não ser apenas um microcosmo do mundo, uma janela através da qual a economia pode ser lida, mas também um espaço com considerável poder para conduzir e moldar a economia através da congregação dos seus esforços (Amin e Thrift, 2007). Estes autores afirmam igualmente que as cidades podem ser vistas como um certo tipo de entidades económicas; um espaço composto com capacidade de composição, em vez de serem consideradas apenas uma entidade que atua como uma esfera económica em seu proveito próprio. É esta dupla condição - cidades como microcosmo e cidades como "campo de força" - integradas em redes com hubs diversos, que está em primeiro plano. Ao considerar a visão oferecida por uma perspetiva de economia cultural, permitimo-nos repensar a economia urbana. Qual a visão defendida para Coimbra, considerando a recente classificação como Património Mundial?

Temos na cidade de Coimbra uma política que considera, como afirmam Graham, Ashworth e Tunbridge (2000), que o Património Cultural pode ser visto nesta forma dual - como um recurso de capital económico e simultaneamente de capital cultural? Ou será que impera a perceção de que o Património Cultural é acima de tudo uma mercadoria vendida aos vários segmentos do mercado?

De forma a explorar os posicionamentos existentes na cidade de Coimbra no que diz respeito aos bens patrimoniais, foram realizadas entrevistas semiestruturadas. Estas entrevistas fazem parte de uma investigação em curso, subordinada ao tema: "Políticas, Intervenções e Representações do Património Cultural em cidades universitárias: o caso de Heidelberg e Coimbra". Foi definido, no âmbito desta investigação, entrevistar os membros da Assembleia Municipal de Coimbra, os Vereadores da Câmara Municipal, os Presidentes das Juntas de Freguesia de Coimbra, entre outros 'stakeholders', como Universidade de Coimbra, Diocese de Coimbra ou Direção-geral do Património Cultural.

As entrevistas semiestruturadas foram realizadas entre janeiro de 2015 e outubro de 2015, seguindo um Guião pré-elaborado que ancorava as questões em cinco tópicos chave: Administração e Enquadramento Jurídico do Património Cultural, Políticas (Locais e Nacionais) do Património Cultural, Representações e Valores do Património Cultural e Estra- 
tégias de Comunicação do Património Cultural. O último tópico dizia respeito às questões sobre Património Mundial. O Guião elaborado para as entrevistas semiestruturadas teve por base a revisão da literatura efetuada, indo ao encontro daquilo que o corpus teórico aponta como principais questões nos cinco domínios do Património Cultural e das quais daremos destaque mais adiante.

A relevância do presente estudo surge na medida em que, como refere Bouchenaki (2014), existe uma crescente e intensa discussão face à rápida mudança nas cidades históricas em muitas partes do mundo. Acrescenta a autora que a discussão se centra actualmente nos novos desenvolvimentos urbanos e arquitectónicos e na forma como as cidades mantêm o seu caráter e identidade histórica. A esta pressão sobre os espaços urbanos acresce, como refere Gomes (2012), o facto de as cidades que enfrentam oportunidades económicas limitadas encararem o turismo como uma alternativa de importância significativa. Este sustenta expetativas de revitalização económica e de desenvolvimento local, através da rentabilização dos bens patrimoniais.

Consideramos que é fundamental compreender os posicionamentos políticos existentes nas diferentes questões centrais do património cultural, até porque, como refere Macdonald (2013), nas últimas décadas os estudos do Património Cultural e os debates em torno deste, desviaram-se do campo da conservação e têm-se centrado no campo das políticas e até de uma fenomenologia do Património Cultural.

Nesse sentido iremos explorar as questões relacionadas com as políticas, mas igualmente as experiências, a forma como os bens patrimoniais são compreendidos e quais os valores que the estão subjacentes face a essas experiências.

No que diz respeito às políticas de Património Cultural, Worthing e Bond (2008), consideram que estas devem ser práticas e passíveis de implementação, avaliando a significância dos bens patrimoniais que lhe estão subjacentes, mas que devem ter também em conta as vulnerabilidades e questões que potencialmente podem afetar os ativos patrimoniais e o seu significado. A premissa é de que só é possível administrar e proteger, valorizando simultaneamente os bens patrimoniais, como referem Worthing e Bond (2008), identificando o que têm de significativo e a forma como esta significância se reflete no todo do lugar. Será que estamos, na perspetiva dos diferentes atores, perante uma visão idêntica no que diz respeito a Coimbra? Os diferentes atores têm uma importância acrescida, na medida em que é necessário conhecer as suas visões sobre os bens patrimoniais, incluindo, como referem Worthing \& Bond (2008), aqueles que foram os proprietários passados e os responsáveis pela gestão presente, os ocupantes do lugar, mas também, os membros da comunidade, do passado e atuais, que usaram os bens patrimoniais, foram associados com, ou se associaram, a estes.

\section{Patrimónios Univers(c)idade}

Em Coimbra, a Universidade é o bem patrimonial por excelência. A Universidade de Coimbra é uma instituição secular criada em 1290 e definitivamente instalada na cidade em 1537. É detentora de um conjunto de bens patrimoniais tangíveis e intangíveis que fazem dela uma das atrações mais procuradas e visitadas na cidade e mesmo em Portugal.

Apesar de a Universidade ser considerada o bem patrimonial mais importante, existe um vasto conjunto de outros bens. Salientam-se os Mosteiros, de Santa Cruz, de Santa Clara-a-Velha e o de Santa Clara-a-Nova; as catedrais, a Velha e a Nova; os conventos, de São Francisco e de Sant'Ana, e Jardins, o Botânico, o Portugal dos Pequenitos, o Parque Verde do Mondego, este ligando as duas margens do rio Mondego, referência fundamental na imagem da cidade e na relação com a colina da Universidade.

Analisando a nomeação como Património Mundial, é preciso ter em mente que esta apenas ocorreu em 22 de junho de 2013. A decisão de classificação foi tomada pelo Comité do Património Mundial na sua trigésima sétima sessão que decorreu em Phnom Penh no Cambodja (UNESCO 2013). A inscrição da "Universidade, Alta e Sofia", de Coimbra, em Portugal foi tomada com base nos critérios (II), (IV) e (VI) através da Decisão ${ }^{\circ} 37$ COM 8B.38.

Com esta decisão, considerou a UNESCO que a candidatura da "Universidade, Alta e Sofia" era uma importante demonstração do intercâmbio dos valores humanos ao longo de séculos, bem como era demonstrativa da influência desta numa área cultural do mundo, da evolução da arquitetura ou da tecnologia, das artes monumentais, do planeamento ou projeto da paisagem (critérios II); de ser um exemplo notável da ocupação tradicional humana, do uso da terra ou do uso do mar, de ser representativa de uma cultura (ou culturas), ou da interação humana com o meio ambiente, especialmente quando se tornou vulnerável sob o impacto de uma mudança irreversível (critérios IV) e que, estava direta ou tangivelmente associada a acontecimentos ou tradições vivas, como ideias, e crenças, com obras artísticas e literárias de significado universal excecional (critérios VI) (UNESCO, 2013).

Resumidamente, são apontadas como razões que levaram à classificação o facto de a Universidade de Coimbra, a Alta e a Sofia terem influenciado de forma determinante as instituições educacionais do antigo império Português ao longo de sete séculos, recebendo e disseminando conhecimentos (II); que a candidatura demonstrava uma tipologia urbana específica, ilustrativa da integração de longo alcance da cidade com a sua Universidade (IV), bem como o facto de este conjunto de ativos ter desempenhado um papel único na formação de instituições académicas no mundo lusófono, através da divulgação das suas normas e formas de organização institucional (VI) (UNESCO 2013). 


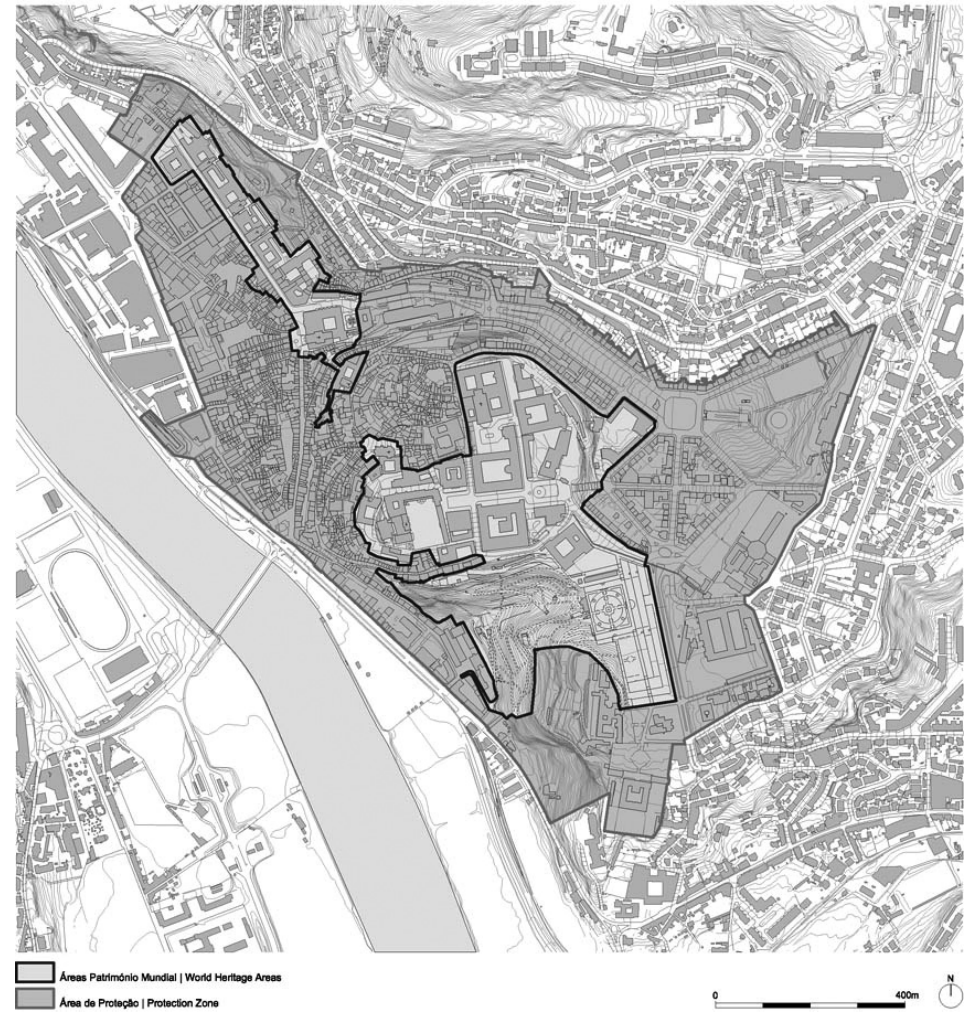

Figura 1

Património mundial e zonas de protecão. Fonte: Associação RUAS, 2014.

O bem patrimonial inscrito na Lista do Património Mundial (Figura 1) ocupa uma área de 35,5 hectares, 29 dos quais correspondem à Universidade e Alta da cidade e 6,5 à Baixa da cidade, mais concretamente, à Rua da Sofia. Esta área delimita um conjunto de edifícios cuja história está ou esteve intimamente associada à Universidade de Coimbra, sejam estes testemunhos da produção e divulgação de conhecimento, ou pelas tradições culturais e identitárias singulares criadas.

Para gerir e monitorizar este conjunto patrimonial classificado como Património Mundial, foi criada a Associação RUAS - Recriar Universidade Alta e Sofia - reunindo, a Universidade de Coimbra, a Câmara Municipal de Coimbra, a Direção Regional de Cultural de Coimbra e a Sociedade de Reabilitação Urbana Coimbra Viva - Empresa Pública de Reabilitação Urbana. Esta associação tem como principal responsabilidade a proteção e salvaguarda do bem patrimonial classificado, bem como o acompanhamento e atualização do Plano de Gestão proposto à UNESCO.

\section{Políticas e estratégias de desenvolvimento}

Que visão política existe para a Cultura e o Património Cultural em Portugal? Por forma a responder a esta questão é pertinente dar expressão ao posicionamento político do estado central, com a análise do Programa para a Legislatura (2011-2015) do XIX Governo Constitucional Português. O programa começa por referir a Cultura como um universo gerador de riqueza, de emprego e de qualidade de vida, considerando ainda a mesma como um instrumento para a afirmação de Portugal na comunidade internacional (Presidência do Conselho de Ministros, 2011).

Se atentarmos, podemos verificar que a área do Património Cultural é apresentada como a herança comum de todos os portugueses, sendo este considerado para além de um importante fator de identidade nacional, e uma das referências fundamentais na educação dos portugueses, acima de tudo como um elemento de enorme potencial para a economia. (Presidência do Conselho de Ministros, 2011).

O programa reconhece ainda que o contributo do património para a sociedade não se esgota na sua contemplação e fruição, sendo necessária uma "manutenção responsável” e valorização do mesmo, a ser promovida com as Autarquias, as Escolas e a Sociedade Civil (Presidência do Conselho de Ministros, 2011). Este posicionamento parece um decalque do direito constitucional, nomeadamente do Artigo $78^{\circ}$, Ponto 1 , da Lei Constitucional n. ${ }^{\circ} 1 / 2005$, de 12 de agosto, que consagra o direito à fruição e criação cultural, bem como o dever de preservar, defender e valorizar o património cultural. 
Apesar de no programa de governo estar delineado que a preservação e valorização do Património Cultural é um dever coletivo do poder central e do poder local, mas igualmente da sociedade civil, como foi possível verificar, a realidade é que esta última tende a remeter as ações de salvaguarda e valorização do Património Cultural para o Estado. Esta tendência poderá ser um reflexo do próprio texto constitucional derivado do estabelecido no Artigo $78^{\circ}$ Ponto 2 Alínea c) da referida Lei Constitucional $n .^{\circ}$ $1 / 2005$, de 12 de agosto, em que incumbe ao Estado o dever de promover a salvaguarda e a valorização do património cultural, tornando-o elemento vivificador da identidade cultural comum.

O Programa de Governo, apesar de reafirmar a necessidade da salvaguarda do património material e imaterial (Presidência do Conselho de Ministros, 2011), não a integra de forma clara numa política de turismo, apesar de referir que a estratégia neste campo se consubstanciará na diferenciação e autenticidade do serviço e do produto turístico. Prevê o Programa que a atratividade do Turismo seja o resultado da articulação de políticas, onde entre outras elencadas, surgem o ordenamento do espaço e a cultura (Presidência do Conselho de Ministros, 2011).

O XX Governo Constitucional Português apesar de ter apresentado um Programa para a Legislatura não o chegou a implementar, pois o seu Programa foi rejeitado através da aprovação de uma das várias Moções de Rejeição apresentada na Assembleia da República (Borga, 2015, novembro 10).

O XXI Governo Constitucional, no seu Programa para a Legislatura (2015-2019) considera a Cultura como um pilar essencial da democracia, da identidade nacional, da inovação e do desenvolvimento sustentado (Presidência do Conselho de Ministros, 2015). A perspetiva com que a Cultura é encarada altera-se, sendo que esta ocupa uma nova centralidade em relação ao Governo anterior passando de uma Secretária de Estado da Cultura, para um patamar superior ao afirmar-se no organograma como Ministério da Cultura.

O novo Governo assume como Missão formular, conduzir, executar e avaliar uma política global e coordenada na área da cultura e domínios com ela relacionados, designadamente, na salvaguarda e valorização do património cultural, entre outras áreas, conforme se encontra expresso no Artigo $19^{\circ}$, Ponto 1 , do Decreto-Lei n. ${ }^{\circ} 251-A / 2015$ que aprova a Lei Orgânica do XXI Governo Constitucional.

Numa leitura mais atenta do Programa é possível verificar que a importância dada à Cultura e ao Património Cultural advém, mais uma vez, de imperativos constitucionais. É visto como essencial o acesso democrático à criação e fruição culturais, à preservação, expansão e divulgação do património material e imaterial (Presidência Conselho Ministros, 2015). Acrescenta o programa que a ação do governo se deve guiar por uma visão que entenda a Cultura como fator essencial de inovação, qualificação e competitividade da economia (Presidência Conselho Ministros, 2015). Assim, de uma visão que apostava na diferenciação e autenticidade (Presidência do
Conselho de Ministros, 2011), passamos a uma visão que instrumentaliza a Cultura como fator de competitividade económica.

Também poderá ser considerada inovadora a consciência da necessidade de um programa de investimento para a recuperação do património histórico (Presidência Conselho Ministros, 2015). Contudo, é claramente salvaguardado que este investimento será a forma de mobilizar outras áreas, entre elas o desenvolvimento regional, o turismo e o comércio externo (Presidência Conselho Ministros, 2015). Este deverá respeitar as hierarquias e prioridades nas intervenções com base numa efetiva monitorização do estado de conservação do Património Cultural (Presidência Conselho Ministros, 2015).

Por último, no que diz respeito à Cultura, o Governo assume a necessidade de uma estratégia concertada de disseminação interna e promoção internacional da Cultura portuguesa capaz de reforçar a imagem externa da riqueza patrimonial e do dinamismo criativo de Portugal (Presidência Conselho Ministros, 2015), podendo uma especialização nacional na área da recuperação do património histórico ser explorada no domínio das exportações de serviços (Presidência Conselho Ministros, 2015).

Impera uma tendência diferente na ação que, de certa forma, instrumentaliza a Cultura e o Património Cultural, para além das suas missões consagradas na Constituição e na Lei de Bases de Proteção e Valorização do Património Cultural. Vai mais longe enquanto veículo de promoção das políticas de emprego, de formação pessoal e profissional, de atração turística e gestão do turismo, essencialmente de competitividade da economia portuguesa e qualidade de vida da sua população.

Perante o exposto, podemos concluir que a política do património cultural, com base na enfâse que é dada à promoção turística nas políticas da cidade em geral, se pode caracterizar como verde-escura ou eco-centrista (Garrod e Fyall, 2000), ou seja, uma política onde a tónica assenta no crescimento económico.

É fundamental ter presente a ideia de que o Património Cultural é hoje essencial à construção do 'branding' e explorado como imagem dos territórios, em especial das cidades. Da mesma opinião partilha Paulo Peixoto (2000) quando afirma que este é importante na formação de novas economias urbanas, nomeadamente através do papel que ele assume no contexto da atividade turística e na promoção das imagens das cidades. Efetivamente, "o impacto na atividade económica, decorrente da chancela UNESCO é positivo na generalidade dos indicadores, sendo plausível concluir que as classificações UNESCO propulsionam benefícios para a região envolvente" (Rebelo e Brito, 2014).

Esta interpretação da cidade enquanto destino turístico está hoje intimamente relacionada com a atração cumulativa, motivada pela densidade da oferta cultural turística em espaços urbanos. No destino urbano é frequente que o turista dirija a sua visita a várias atrações. Hunt e Crompton (2008) definiram o conceito de 'viagem multiatração' que 
tem no destino urbano o seu palco por excelência, até porque um destino é um produto complexo de combinação de recursos, produtos e atrações.

As atrações fornecem, de facto, os elementos centrais para o desenvolvimento de um destino enquanto produto turístico e são componentes motrizes do sistema turístico constituindo o foco da atenção do visitante, como "must see" ou "must do" que estão na origem da motivação inicial do turista na visita ao destino (OMT, 2007, citado por Caldeira, 2015).

"O destino passa a ser visto como um local de aprendizagem e não apenas local de descanso e fuga à rotina, o desenvolvimento e contacto com outras culturas são metas primordiais da viagem, tornando o turista num consumidor de 'edutenimento', ou seja, 'entretendo-se aprendendo' (Santos, 2014).

As estratégias de ação com intervenções 'bottom-up' e 'top-down' precisam de se conjugar, porque o grande aumento da oferta turística deixa os destinos mais débeis em matéria de posicionamento, especialmente se dependentes exclusivamente dos seus recursos endógenos. É preciso poder contar com todas as estratégias capazes de criar inovação, singularidade e experiências memoráveis (Santos, 2013), dando lugar à expressão emotiva do visitante.

Um documento orientador ao nível da planificação e estratégia de desenvolvimento local é o Plano Estratégico de Coimbra. Este pretende ser um instrumento de concertação estratégica que perspetiva o papel de Coimbra no contexto do sistema metropolitano, regional, nacional e internacional, tendo sido aprovado por maioria na Assembleia Municipal de Coimbra de 12 de janeiro de 2011, sob proposta da Câmara Municipal de 12 de abril de 2010.

O Plano Estratégico de Coimbra aponta que os objetivos de Desenvolvimento Económico Sustentável, Inovação e Conhecimento devem ser orientados por três áreas estratégicas: Saúde e Engenharia; Conhecimento e, por último, Turismo. A área do Turismo é apresentada como potenciadora, dado o património de Coimbra ao nível ambiental, edificado histórico e de cultura e entretenimento (Deloitte, 2007). Aponta o citado plano que o Turismo e o Património Edificado devem, para além de serem encarados como alavancas estratégicas, integrar os objetivos estratégicos, numa política potenciadora de desenvolvimento. É necessário ter presente como referem Graham, Ashworth e Tunbridge (2000), que o Património Cultural é conhecimento, um produto cultural, mas igualmente como um recurso político.

O Plano Estratégico de Coimbra, no seu Documento Complementar (Deloitte, 2009), aponta a candidatura da Universidade a Património Mundial como importante, num contexto de recuperação e valorização do Património Monumental da Universidade de Coimbra. Salienta, também, que se esperavam efeitos significativos no médio prazo ao nível da promoção turística da Cidade, acrescentando mesmo que esta candidatura, entre outras medidas, era essencial para combater o progressivo despovoamento demográfico e degradação urbana que o centro histórico de Coimbra tem vindo a sofrer (Deloitte, 2009). Estamos, pois, neste caso, perante um exemplo de como o Património Cultural, tido originalmente com a finalidade de representar o passado, toma proporções maiores, com o propósito turístico (Rocha e Monastirsky, 2008).

Este instrumento de planificação estratégica aponta ainda que o Centro Histórico de Coimbra é composto por três unidades geográficas, a referir: Alta, Baixa e Santa Clara Monumental, sendo o mesmo caraterizado como um espaço com uma densidade de arquitetura monumental e museológica muito significativa (Deloitte, 2009).

Entre as diferentes Macro Ações a implementar (Deloitte, 2009), e no que concerne ao Património Cultural, o Plano Estratégico de Coimbra dá destaque, a duas enquadradas no Vetor de Intervenção - Marca, Turismo, Cultura, Património e Desporto, a referir a Política de Marca e os Ativos Patrimoniais. Surge-nos ainda no Vetor de Intervenção - Dinâmicas Urbanas, Sociais e Ambiente, a Macro Ação Centro Histórico. (Deloitte, 2009).

A Macro Ação, Centro Histórico, integrada no Vetor de Intervenção - Dinâmicas Urbanas, Sociais e Ambiente, prevê a necessidade de intervenção na Baixa e na Alta da Cidade (Deloitte, 2009). Estas intervenções são consideradas como estruturantes na prossecução do Plano Estratégico de Coimbra.

É defendida, no que concerne à Baixa da cidade, a requalificação da oferta habitacional e a dotação do pequeno comércio tradicional de condições para adequar a oferta às necessidades e os padrões de exigência dos novos residentes, trabalhadores e visitantes.

No que concerne à Alta a refuncionalização dos espaços libertados pela Universidade de Coimbra como espaços de animação noturna é vista como uma ação que irá combater o despovoamento, sobretudo noturno, de algumas zonas da Alta, evitando que se formem pólos de marginalidade e insegurança. A aposta deverá passar igualmente pela constituição de equipamentos turísticos, hotéis de charme e complementados por bares, esplanadas e restaurantes.

Pressupõe o Plano que a não realização destas ações implicaria uma falha enorme ao nível da reabilitação urbana e coincidentemente ao nível da qualidade de vida, imagem de marca e captação de turismo (Deloitte, 2009), para além de que inviabilizará claramente revitalização do Centro Histórico pondo em causa a salvaguarda da memória do passado de uma cidade, sem a qual é impossível criar uma identidade (Deloitte, 2009).

No que concerne à Política de Marca, considera o Plano que é relativamente fácil a associação da cidade a lugares físicos, naturais e patrimoniais, bem como a uma dimensão cultural e histórica. No entanto, a Marca Coimbra está excessivamente conotada com a dimensão histórica e demasiado dependente da Universidade e da sua ligação à Saúde. (Deloitte, 2009).

O desenvolvimento da imagem de Marca de Coimbra é considerado prioritário e até estruturante 
na implementação do Plano Estratégico e este passa essencialmente por três ações de planeamento, a referir: desenvolvimento de uma Marca para Coimbra, desenvolvimento de uma política de promoção turística da região e, por último, pela candidatura do conjunto monumental da Universidade de Coimbra a Património Mundial.

A Candidatura do conjunto Monumental e Património imaterial da Universidade de Coimbra a Património Mundial da UNESCO (Deloitte, 2009) é uma Ação considerada estruturante para o sucesso do Plano Estratégico de Coimbra. Está enquadrada dentro da Macro Ação das Políticas de Marca que é entendida como essencial para a projeção de Coimbra enquanto centro difusor da lusofonia, enquanto forma de potenciar a sua projeção internacional, nos domínios do património físico, mas igualmente do seu vasto património intangível (Tradições culturais da cidade e Academia e Língua e Cultura portuguesas), e por último como forma de prevenir a agressão patrimonial e a dispersão da memória coletiva. Considerava-se, à data, que a eventual classificação de Património Mundial poderia ser um catalisador e mobilizador da ação de preservação, mais igualmente de consciencialização da comunidade coimbrã para com o seu Património Cultural.

Considera-se que a não concretização desta ação em concreto poderá atrasar as prementes intervenções de recuperação urbanística, na perspetiva que uma não classificação como Património Mundial bloquearia o acesso a apoios comunitários que uma elevação iria permitir, bem como, que um dos pilares da projeção internacional de Coimbra como destino turístico estaria comprometido (Deloitte, 2009). O definido em sede de planeamento estratégico vai ao encontro do facto, como refere Paulo Peixoto (2003), de que o património se tornou num recurso incontornável nas estratégias de definição de uma imagem de marca, acrescentando que ele próprio enquanto marca define à partida um certo valor concorrencial e comunicacional intrínseco aos territórios.

No entanto, temos que ter em conta, como afirma Richards (1996) que as áreas do património tradicionais ainda têm uma vantagem considerável sobre as 'novas' áreas de património por causa do valor simbólico e estético acumulado.

Assim, não se compreende que a Macro Ação denominada de Ativos Patrimoniais esteja essencialmente alicerçada por três ações, fundamentalmente voltadas para a atividade turística e que passam: pela implementação do Coimbra Card, pela exploração comercial de espaços históricos, e por último, pela valorização do conjunto monumental de Coimbra. Antevê-se, desde logo, no Plano Estratégico que o principal obstáculo à rápida aplicação deste conjunto de ações seja o conjunto de procedimentos burocráticos que envolvem sempre qualquer intervenção sobre o Património Histórico.

Fica claro, no que concerne à Ação -Valorização do Conjunto Monumental de Coimbra (Deloitte, 2009), com a planificação global do conjunto de ativos, a definição de um conjunto de roteiros turísticos e por último a promoção do acervo museológico da cidade, enquanto ação de apoio à implementação do Plano Estratégico de Coimbra, a sua não realização não assume um carácter estrutural para o plano.

É igualmente assumido que o conjunto de bens patrimoniais da cidade, considerados como fatores atrativos turísticos, se devem constituir alavancas e uma política de promoção turística.

A necessidade de preservação dos bens patrimoniais é considerada indissociável, no Plano Estratégico de Coimbra, da necessidade da sua promoção turística. Este facto está expresso até na Prioridade conferida a cada ação, e desde logo pelo facto de considerar a implementação do Coimbra Card (Deloitte, 2009) como prioritário, ou seja, como uma ação com um impacto muito significativo sobre a consecução dos Objetivos Estratégicos do Plano, sendo as restantes ações referidas remetidas para nível de prioridade mais baixo.

Prevê-se, desde logo, a necessidade de, para um conjunto de bens patrimoniais, se proceder a intervenções que possibilitem as alterações de uso em prol de atividades comerciais compatíveis (Deloitte, 2009). A estratégia de reutilização adaptativa de monumentos históricos, como refere Bouchenaki (2014), tem sido seguida em diversos centros históricos das cidades, e a mesma tem-se revelado eficaz e ajudou a rejuvenescer a base económica das antigas partes de diferentes cidades, gerando receita e oportunidades de emprego. Estamos, neste sentido, perante um Plano Estratégico que consagra a necessidade de refuncionalização dos bens patrimoniais. Como refere Peixoto (2003), as estratégias de refuncionalização do passado, oscilando entre a reativação, a reinvenção e a idealização, adquirem formas diversas. No entanto, as estratégias de preservação do Património Cultural observáveis em contexto urbano tendem, em nossa opinião, a atender mais aos interesses económicos que têm como propósito concreto a utilização do património em função da atividade turística, do que atender aos interesses ideológicos ligados à conservação da memória e da identidade local, igualmente apontados por Rocha e Monastirsky (2008). Da mesma opinião partilha Bouchenaki (2014), quando enfatiza a necessidade de harmonizar as novas necessidades económicas e sociais dos habitantes com a paisagem urbana original, sem comprometer a identidade e autenticidade, acrescentando que este é o maior desafio que se coloca aos diferentes atores no terreno.

Um outro documento importante no que concerne as políticas e intervenções a desenvolver é a Estratégia de Reabilitação Urbana, instrumento formal definido pela Câmara Municipal de Coimbra. Este instrumento define que a estratégia de reabilitação da Alta da cidade e do Centro Histórico se enquadra numa estratégia urbana mais vasta, procurando dar resposta às ambições da cidade nas suas diferentes escalas territoriais, consolidando Coimbra como: a) a cidade do conhecimento; b) uma nova metrópole; e c) a cidade do Mondego (Parque Expo, 2012b). 
Sobre o lema 'Re:Centrar o Centro Histórico de Coimbra', a Estratégia de Reabilitação Urbana (Parque Expo, 2012a) incorpora o Património Cultural como o quinto dos seus objetivos estratégicos. A valorização do edificado patrimonial da Rua da Sofia e o apoio ao processo de candidatura do centro histórico a Património Mundial são destacados de forma inequívoca. Os projetos como 'Coimbra Património Ativo' e 'Polo 0 - Rua da Sofia', entre outros, são considerados como projetos estruturantes pela reabilitação e refuncionalização dos bens patrimoniais existentes.

O desenvolvimento do turismo é entendido como o sexto objetivo estratégico (Parque Expo, 2012a), sendo que se aponta como necessária, entre outros, a valorização e articulação do património edificado numa ótica de exploração turística, bem como, a valorização da Universidade de Coimbra enquanto grande polo de atração cultural e turística.

Esta abordagem surge mesclada nos objetivos do Gabinete para o Centro Histórico $(\mathrm{GCH})$ que com a sua atividade promove e executa estudos, projetos e ações no sentido da salvaguarda do património histórico e arquitetónico existente na área do Município. Tem também por função divulgar projetos tendentes à defesa e recuperação do património histórico e arquitetónico; elaborar, propor e divulgar regras de intervenção urbanística nas zonas históricas e apoiar intervenções de carácter social inerentes ao desenvolvimento das intervenções nas zonas históricas CMC (2007, setembro 13).

É preciso salvaguardar que os investimentos em Património Cultural não estão dependentes da temporalidade da ação, como refere Mejías López (2008), e que o conjunto de intervenções e planos de requalificação com o seu investimento não se realize segundo critérios conjunturais e pequem por não cobrir a insuficiência das necessidades planeadas. Como aponta Russo (2002), os decisores políticos têm que ter consciência dos movimentos estratégicos que são necessários em cada situação específica, bem como de que estes e o ciclo de vida não têm resultados imediatos, a menos que se considerem expressamente as características dos locais e os seus recursos. A conceção vigente (Henriques, 1996) é de que o turismo pode funcionar como fator de revitalização de certas áreas particulares da cidade, nomeadamente dos centros históricos. De forma concreta, a vertente cultural do turismo, genericamente referida como turismo cultural pode ser definida como "uma forma de turismo que se baseia nos bens do Património Cultural de um destino e os transforma em produtos de forma a serem consumidos por turistas" (McKercher e Du Cros, 2005 citado por Du Cros e McKercher 2015).

Assim, para além da necessidade de se compreender o que é o turismo, importa reconhecer a importância do uso dos bens culturais existentes em cada lugar, promover o consumo de experiências e de produtos, motivo de atração 'push' (empurrar) e 'pull' (puxar) (Burns, 1999) perante o visitante turista. Percebe-se, pois, que o "produto turístico é complexo porque mistura elementos de serviço, de hospitalidade, de livre escolha, do envolvimento do consumidor e o consumo de experiências" (Du Cros e McKercher, 2015). Exigindo o turismo cultural ainda mais atenção, na perspetiva de que qualquer ativo de turismo cultural ao ser projetado para o consumo dos turistas deve ser pensado como um produto e gerido em conformidade, o processo começa com a identificação das necessidades nucleares que se querem satisfazer, para de seguida, ser capaz de servir essa necessidade, de forma significativa, através de uma aposta na qualidade e experiência consistente (Du Cros e McKercher, 2015).

A Estratégia de Reabilitação Urbana permite, precisamente, valorizar este entendimento de turismo cultural e, por isso, considera que é necessário dotar o parque edificado de condições de utilização adequadas, através de obras e beneficiações, para as diversas funções que o mesmo serve (Parque Expo, $2012 b)$. As operações de reabilitação deverão orientar-se, segundo o documento, no sentido da criação de condições, para que os privados procedam às intervenções e se instalem no centro histórico.

Como objetivos da intervenção (Parque Expo, 2012b), destacam-se entre outros, a reabilitação do parque edificado, consolidando os programas de apoio aos proprietários, a promoção da ocupação dos edifícios devolutos, designadamente dos edifícios mais emblemáticos, através de uma refuncionalização, e ainda a reabilitação das "Repúblicas" de estudantes e promover a instalação de novas residências para estudantes e unidades de alojamento local.

Este posicionamento ao nível dos instrumentos de planeamento vem ao encontro do defendido por Vinuesa (2004) quando considera que são necessárias conexões mais estreitas entre as políticas de recuperação dos conjuntos históricos e das suas novas funcionalidades, ou seja, que é necessário conectar mais estreitamente as dimensões urbanísticas, económicas, turísticas e culturais.

Este instrumento de planeamento define, igualmente, a necessidade de um conjunto de apoios e incentivos de natureza fiscal, quer municipais, quer nacionais, (Parque Expo, 2012b) como a isenção por um período de cinco anos de Imposto Municipal sobre Imóveis e a isenção de Imposto Municipal sobre as Transmissões Onerosas de Imóveis na primeira transmissão onerosa após a reabilitação, quando o bem intervencionado se destinar a habitação própria e permanente. Outro tipo de incentivos previstos é, por exemplo, a dedução à coleta, em sede de IRS, e a isenção de IRS e IRC sobre rendimentos obtidos por Fundos de Investimento Imobiliário. Ao nível dos incentivos fiscais, todas as intervenções efetuadas na área de reabilitação definida estão ainda abrangidas pela taxa reduzida de $6 \%$ no que diz respeito ao IVA (Parque Expo, 2012b).

\section{Perceções planeadas e caminhos definidos}

Como referido acima, por forma a averiguar os posicionamentos dos diferentes atores no território, foram realizadas entrevistas semi-estruturadas com os deputados municipais, com assento na Assembleia 
Municipal, com os Vereadores da Câmara Municipal de Coimbra, bem como com a Vice-Reitora da Universidade de Coimbra responsável pela área de Comunicação, Cultura e Património.

Considera Manuel Rocha, deputado municipal (Rocha, comunicação pessoal, março 4, 2015), a propósito das questões de financiamento, uma ideia macabra, a ideia de que a sobrevivência da Cultura e do Património Cultural possa estar dependente da 'massa monetária' dada pelo Turismo. Acrescenta mesmo que o turismo, enquanto unidade orgânica, não tem que estar ligado ao património, na medida em que é uma área completamente distinta deste. Por seu lado, o turismo, agente de desenvolvimento económico e de desenvolvimento promocional, não tem que estar necessariamente ligado ao património (M. Rocha, comunicação pessoal, março 4, 2015).

Da mesma opinião partilha Nuno Vassallo e Silva, diretor-geral do Património em Portugal (Salema e Canelas, 2015, março 10) quando afirmou que o turismo está a criar alguma pressão sobre zonas classificadas, sobre a utilização de edifícios históricos, acrescentando que é preciso dizer de forma explícita que recuperar apenas para fins turísticos não é solução que seja aceitável para a Direcção-Geral do Património Cultural.

A mercantilização do património constitui-se como um problema, na medida em que o património transformado em produto de consumo só será acessível por via dos novos usos ou das novas funções e privilegiará o acesso e desfrute dos setores da população com maior disponibilidade de recursos. Está-se, como refere Carvalho (2003), perante uma hipotética subtração do bem cultural ao seu contexto sociocultural. É ainda necessário ter presente a ideia de que a subtração de equipamentos urbanos aos moradores (Russo, 2002), mas também dos locais de interesse cultural, despoleta problemas diversos entre os 'stakeholders' turísticos. Todavia, importa referir que políticas de segregação positivas para as populações residentes são fáceis de aplicar e podem prover o serviço público associado aos bens culturais.

A propósito das intervenções em Património Cultural Jorge Barreto Xavier (Carvalho, 2014, março 12), na qualidade de Secretário de Estado da Cultura, tinha já alertado que não é possível, devido à riqueza do nosso património, ter tudo resolvido, mas que a tutela tem trabalhado atentamente para garantir o apoio à preservação do Património.

No que concerne a esta relação entre Turismo e Património Cultural, Carina Gomes, Vereadora do Executivo da Câmara Municipal de Coimbra e responsável pelos pelouros Turismo, Juventude, Ação Cultural e Gestão de Espaços Culturais, refere que está provado que há uma correspondência entre os países que são os principais destinos de turismo internacional e os países que têm mais bens classificados como Património Mundial pela UNESCO (Gomes, comunicação pessoal, março 10, 2015).

As motivações de viagem criadas em torno do Património Cultural e da patrimonialização de lugares fazem com que a procura aumente significativamente e sejam cada vez mais os turistas do patrimó- nio. Os sítios Património Mundial da UNESCO têm uma grande responsabilidade neste crescimento, tanto como atração como divulgadores da tipologia. Neste contexto, Chandler e Costello (2002) explicitam que a popularidade do Turismo Patrimonial se deve a vários fatores, mas todos tendem a concordar que os turistas patrimoniais querem mais experiências culturais e patrimoniais, sejam as mesmas experiências significativas e autênticas ou formas de superficial entretenimento (Chandler e Costello, 2002). No entanto, Poria, Butler e Aurey (2004) são mais assertivos na importância da escolha pessoal por este tipo de turismo e referem que este deve ser entendido com base na relação gerada entre o indivíduo e o património apresentado (...), onde a perceção do sítio pelos turistas deve corresponder a uma perceção de pertença.

Esta perspetiva vai ao encontro da interpretação de Carina Gomes (comunicação pessoal, março $10,2015)$ sobre a recente classificação como Património Mundial que o título trouxe um reconhecimento ainda maior à cidade, um aumento imediato dos níveis de procura turística, salvaguardando, igualmente, que esta distinção traz consigo uma série de preceitos que agora têm que ser cumpridos, destacando que o título não é o fim de nada, é o princípio de muita coisa (Gomes, comunicação pessoal, março 10, 2015).

Numa análise ao planeamento num quadro geral e nacional, sobre a questão do turismo cultural, Clara Almeida Santos, Vice-Reitora da Universidade de Coimbra, considera que a mais-valia do país reside aí. Acrescenta que "é aí que nós somos mesmos fortes", pelas mais-valias que os nossos patrimónios naturais e culturais constituem (Santos, comunicação pessoal, setembro 10, 2014).

A Universidade de Coimbra, enquanto produto turístico, é entendida, por Clara Almeida Santos, como o evoluir de um processo de abertura à sociedade. Considera que o Turismo "foi, até há duas décadas, um dano colateral da Universidade de Coimbra. Havia umas senhoras que abriam as portas". Acrescenta, ainda, que se "fez um caminho gigante, desde há 20 anos, mas ainda há muito que fazer, de facto, nunca estará acabado" (Santos, comunicação pessoal, setembro 10, 2014).

Dadas as limitações de financiamento ao Ensino Superior em Portugal, é igualmente expresso pela Vice-Reitora que é completamente impossível que a receita gerada pelo circuito turístico seja aplicada, exclusivamente, no circuito turístico. A mesma é direcionada para o pagamento do funcionamento da instituição (Santos, comunicação pessoal, setembro 10, 2014). Desta visão partilha, Manuel Rocha quando afirma que "o dinheiro que é dado à universidade para o seu funcionamento, por exemplo, não tem em vista o desempenho do papel de conservação do património" (Rocha, comunicação pessoal, março 4, 2015).

Compreende-se, assim, esta visão instrumentalizadora do Património Cultural da Universidade até pela necessidade de aproveitar o efeito poten- 
ciador que a classificação veio trazer no contexto local.

A classificação como Património Mundial pela UNESCO da 'Universidade, Alta e Sofia', agrupa visões diferentes, que para além de colocar Coimbra no "mapa, num mapa civilizacional” (Rocha, comunicação pessoal, março 4, 2015), traz consigo, como refere Nuno Freitas, deputado municipal (comunicação pessoal, abril 11, 2015), sentimentos de "orgulho, de uma certa vaidade" sendo que vem, da mesma forma, "estruturar, coordenar e interligar atores" nos domínios da gestão e administração deste património cultural. Deve a mesma constituir-se como "uma alavanca para um outro patamar, para outro envolvimento da cidade, para o desenvolvimento da cidade (Freitas, comunicação pessoal, abril 11, 2015).

Raimundo Mendes da Silva, Vereador da Câmara Municipal de Coimbra, acrescenta que com esta distinção "herdamos um conjunto de responsabilidades culturais, políticas, e sociais" na medida em que "um selo da UNESCO é um elemento de desenvolvimento local, nacional, mundial" e deveria, em seu entender, ser ainda "uma bandeira para a universidade portuguesa em geral” (Silva, comunicação pessoal, fevereiro 26,2015 ).

0 entendimento geral é de que, no contexto da cidade de Coimbra, ainda existe muito trabalho, apesar do já feito, para "diversificar a experiência turística da cidade", sendo que é "necessário ter cada vez mais conteúdos para que esses possam ser promovidos" (Gomes, comunicação pessoal, março 10, 2015). Outro aspeto salientado por Raimundo Mendes da Silva é o facto de "os estudos, o trabalho organizativo, os planos de ação, os planos de gestão, os planos diretores" elaborados, tendo em conta a candidatura a Património Mundial, estão agora "disponíveis para quem quiser fazer gestão do bem, a gestão da cidade", um benefício "proporcionado desde logo pela candidatura” (Silva, comunicação pessoal, fevereiro 26, 2015).

Por último, coloca-se uma questão nas estratégias de gestão, administração e programação dos bens patrimoniais da cidade, e esta pode ser formulada do seguinte modo: que quer ser Coimbra enquanto Património Mundial? Como refere Raimundo Mendes da Silva é também necessária a resposta à questão "quer ser património mundial para atrair pessoas, e para ter um papel, por exemplo, do ponto de vista turístico, de animação e de distribuição turismo para a região Centro, ou quer ser um polo de concorrência?" (Silva, comunicação pessoal, fevereiro 26, 2015).

\section{Conclusões}

Com este artigo pretendemos proceder à análise, através da revisão da literatura e de entrevistas semiestruturadas, das possibilidades que os bens patrimoniais da cidade têm, bem como da forma como a promoção e políticas de salvaguarda existentes podem sustentar ou interromper as diferentes iniciativas de desenvolvimento existentes. Estamos em crer que ficou clara a necessidade de repensar o plano estratégico de desenvolvimento da cidade de Coimbra, à luz da nova realidade aduzida pela classificação como Património Mundial.

Antes de discutir as contribuições sobre a forma de conclusões, será importante referir que o presente estudo ao cingir as entrevistas semiestruturadas aos intervenientes políticos, poderá descurar um conjunto de atores no território que podem de certa forma ajudar a consolidar uma política e plano de desenvolvimento para a cidade, conforme a revisão bibliográfica nos indica. Seria pertinente numa fase de aprofundamento ulterior dar voz às associações comerciais e industriais da cidade, às associações e grupos académicos, mas também às associações de moradores. Este aprofundamento da análise permitirá pormenorizar as conclusões e poderá trazer contribuições válidas que não tenham sido tidas em conta, influenciando uma política de Património Cultural de cariz mais holístico, pelo menos no que diz respeito à comunidade que o vive e vivência.

A primeira conclusão evidente do exposto é a multiplicidade de atores e agentes presentes no contexto territorial da cidade que, quando não inviabilizam as intervenções, lhe colocam pelo menos dificuldades acrescidas.

A inexistência de um departamento dedicado especificamente às tarefas relacionadas com a gestão do Património Cultural da cidade é deficit estratégico dificilmente superável, como refere Mejías López (2008). A existência da Associação RUAS visa, por princípio, combater esta desarticulação estrutural existente no contexto, no entanto, a sua intervenção restringe-se às áreas classificadas como $\mathrm{Pa}$ trimónio Cultural, excluindo um conjunto vasto de bens patrimoniais da cidade e que foram convenientemente integrados no Plano Estratégico de Coimbra, e parcialmente na Estratégia de Reabilitação Urbana.

A perspetiva contemporânea de interpretação particularmente instrumentalista da economia cultural (Sassen, 2001; Taylor, 2004; citado por Amin e Thrift, 2007), em que as cidades se transformam em destinos turísticos de referência, cuja competitividade depende, de modo significativo, dos elementos patrimoniais que agregam e estruturam como produtos, parece estar, igualmente, presente nos posicionamentos e entrevistas apresentadas. Os bens patrimoniais da cidade são, claramente entendidos, como componentes de desenvolvimento e regeneração urbana.

Fica, igualmente, patente que os diferentes posicionamentos apresentados sustentam uma consciência, da estreita relação entre o esforço na conservação e uma maior ou menor afluência turística, como defendido por Vinuesa (2004).

Transversal à documentação e entrevistas analisadas, é igualmente patente a necessidade de organizar a cidade, de a requalificar, por forma a dar resposta às necessidades daqueles que a vivificam, sem descurar a procura crescente, seja de turismo externo ou interno, maioritariamente considerada como um fator de desenvolvimento para a cidade. 
O Centro Histórico surge como a principal área turística de Coimbra, sendo o Turismo Cultural Urbano, Patrimonial e Histórico, o mais relevante. Um inquérito aos visitantes de Coimbra, realizado em 2011 pela Camara Municipal de Coimbra e pela Área de Turismo do Departamento de Geografia da Faculdade de Letras (citado por Santos, 2013), mostra que existe uma grande diversidade e qualidade da oferta. Para os turistas, as atrações de Coimbra estão intimamente relacionadas com o Centro Histórico, ancoradas na Universidade (Polo I). São o Património Monumental, a Vida Académica, a Topografia e o Rio Mondego que se destacam. Existe um reforço da competitividade da oferta do Património Religioso (material e imaterial) enquanto produto turístico: a Igreja de Santo António dos Olivais e o Convento de Santa Cruz, as festas da Rainha Santa Isabel, a Irmã Lúcia, associada ao Carmelo de Santa Teresa. Em todos estes elementos de valorização turística, a cultura e o património são incontornáveis e bases fundadoras de todos os processos (Santos, 2013).

Concordamos com Poria, Reichel e Biran (2006) quando afirmam que deve ser dada especial atenção à perceção que os turistas têm da relação entre os sítios de património e a sua própria herança patrimonial, elemento fundamental no condicionamento do comportamento durante a visita. Por isso mesmo, não devemos assumir que os visitantes de bens patrimoniais como um segmento homogéneo, pelo que consideramos que a organização e o planeamento urbanístico, o meio ambiente, a oferta cultural, as rotas e itinerários, bem como os equipamentos e infraestruturas turísticas, assumem um papel fundamental na gestão da oferta patrimonial. Fica claro que, ao nível dos instrumentos de gestão e planeamento da cidade de Coimbra, bem como ao nível dos posicionamentos, essa perspetiva está salvaguardada.

Não podemos concordar que no contexto territorial da cidade de Coimbra, a visão tida com o património seja essencialmente guiada por conservar o estado pristino dos bens culturais e patrimoniais, como afirmam Garrod e Fyall (2000), nem tão pouco que as questões relativas à sustentabilidade financeira e o acesso público sejam relegadas para segundo plano no que concerne à tomada de decisões. Pelo contrário, como pudemos demonstrar, a principal preocupação é exatamente a sustentabilidade das intervenções, bem como a necessidade de refuncionalizar todo um conjunto de bens patrimoniais.

Ao longo do presente artigo, verificamos que, quer os documentos orientadores ao nível do planeamento estratégico da cidade, quer as perceções que os diferentes atores revelaram da cidade, consideram a necessidade de novos usos para os bens patrimoniais existentes, de forma a salvaguardar a sua significância cultural. Ficou ainda demonstrada a visão de que só será possível à cidade o desenvolvimento económico através de uma instrumentalização do Património Cultural em favor de uma demanda turística, que se deseja e crê vir a intensificar com a classificação como Património Mundial.
Aliando-nos da perceção do Património Cultural enquanto recurso económico, será um desafio, para os diversos atores como tivemos ocasião de referir, responsáveis pela gestão do Património Cultural na cidade, o conciliar das divergências e conflitos entre uma visão economicista destes recursos e a sua conservação. Isto é tanto mais difícil quanto o papel crescente que o património tem sido chamado a desempenhar no desenvolvimento, em especial por causa da diversificação e qualificação da oferta turística, que em muitas regiões e cidades se constitui como uma importante fonte de receita e de emprego, associada à identidade, a sustentabilidade e à notoriedade.

\section{Bibliografia}

Amin, A. \& Thrift, N. (2007). Cultural-economy and cities. Progress in Human Geography 31(2), 143-161.

Associação RUAS (2014). O Bem | The Property. Retrived from: http://www.uc.pt/ruas/property.

Borga, M. (2015, novembro 10). Governo caiu na Assembleia. Decisão nas mãos de Cavaco. Retrieved from:http:// expresso.sapo.pt/política/2015-11-10-Governo-caiuna-Assembleia.-Decisao-nas-maos-de-Cavaco.

Bouchenaki, M. (2014). Cultural heritage and sustainable development. In Elena Korka (ed), The protection of archaeological heriatge in times of economic crisis (pp. 2-9). Cambridge: Cambridge Scholars Publishing.

Burns, P. M. (1999). An introduction to tourism and anthropology. London: Routledge.

Caldeira, A. (2014). A experiência de visita dirigida às múltiplas atrações: análise do comportamento espacial do turista e da sua satisfação. Tese Doutoramento não Publicada, Departamento de Economia, Gestão e Engenharia Industrial. Universidade de Aveiro, Aveiro.

Carvalho, C. L. (2014, março 12). Conservação do património é prioridade para 2014, diz Barreto Xavier. Jornal Público. Retrieved from http://www. publico.pt/ culturaipsilon/noticia/conservacao-do-patrimonio-eprioriadade-para-2014-diz-barreto-xavier-1628079.

Carvalho, P. (2003). Património e território: dos lugares às redes. In Actas do V Colóquio Hispano Português de Estudos Rurais. Bragança, Escola Superior Agrária de Bragança -Sociedade Portuguesa de Estudos Rurais/ Asociación Española de Economia Agrária.

Chandler, J. \& Costello, C. (2002). A profile of visitors at heritage tourism destinations in East Tennessee according to Plog's Lifestyle and Activity Level Preferences Model. Journal of Travel Research, 161166.

CMC (2007, setembro 13). Gabinete para o centro histórico. Retrieved from: http://www.cm-coimbra.pt/index. 
php/gabinete-para-o-centro-histrico-menuurbanismo-455.

Decreto-Lei n. ${ }^{\circ} 251$-A/2015, de 17 de dezembro. Diário da República N. ${ }^{\circ}$ 246/2015 - I Série A. Assembleia da República. Lisboa.

Deloitte, Vasco da Cunha (2007). Plano estratégico de Coimbra. Diagnóstico final. Câmara Municipal de Coimbra. Retrieved from: https://www.cm-coimbra. pt $/$ index.php?option $=$ com_docman\&task $=d o c \_$ download\&gid $=1148 \&$ Itemid $=$.

Deloitte, Vasco da Cunha (2009). Plano estratégico de Coimbra. Documento complementar. Câmara Municipal de Coimbra. Retrieved from: https://www.cm-coimbra. pt $/$ index.php?option=com_docman\&task=doc_ download\&gid $=2923 \&$ Itemid $=$.

Du Cros, H. \& McKercher, B. (2015). Cultural tourism. New York: Routledge.

Garrod, B. \& Fyall. A. (2000). Managing heritage tourism. Annals of Tourism Research, vol. 27, n 3, 682-708.

Gomes, C. (2012). Novas imagens para velhas cidades? Coimbra, Salamanca e o turismo nas cidades históricas. Sociologia, Revista da Faculdade de Letras da Universidade do Porto. vol. XXIII, 37-49.

Graham, B. (2002). Heritage as knowledge: capital or culture?. Urban Studies, vol. 39, ns 5-6, pp. 1003-1017.

Graham, B.; Ashworth, G. J. \& Tunbridge, J. E. (2000). A geography of heritage: power, culture and economy. London: Arnold.

Heinich, N. (2009). La fabrique du patrimoine: de la cathédrale à la petite cuillère. Charenton-le-Pont: Editions de la Maison des sciences de l'homme.

Heinich, N. (2011). The making of cultural heritage. Nordic Journal of Aesthetics. vol. 22, 40-41.

Henriques, E. B. (1996). Turismo, património e cidade: da revitalização urbana ao risco de manipulação das paisagens. In C. Cavaco, (coord), Turismos e lazeres (pp. 54-65). Lisboa: Centro de Estudos Geográficos da Universidade de Lisboa, 1996. ISBN 972-636-112-5.

Hunt, M. \& Crompton, J. (2008). Investigating attraction compatibility in an East Texas city. International Journal of Tourism Research, 10, 237-246.

Lei Constitucional n. ${ }^{\circ} 1 / 2005$, de 12 de agosto. Diário da República N. ${ }^{\circ}$ 155/2005 - I Série A. Assembleia da República. Lisboa.

Macdonald, S. (2013). Memorylands. Heritage and identity in Europe today. London: Routledge.

Mejías López, J. (2008). Estructuras y principios de gestión del patrimonio cultural municipal. Gijón: Ediciones Trea, ISBN 978-84-9704-358-8.
Parque Expo (2012a). Parte I - Visão para o centro histórico. A estratégia de reabilitação urbana. Coimbra.

Parque Expo (2012b). Parte II - Estratégia de reabilitação urbana. A estratégia de reabilitação urbana. Coimbra.

Peixoto, P. (2000). Gestão estratégica das imagens das cidades: análise de mensagens promocionais e de estratégias de marketing urbano. Revista Crítica de Ciências Sociais, 56, pp. 99-122.

Peixoto, P. (2003). Centros históricos e sustentabilidade cultural das cidades. Sociologia: Revista da Faculdade de Letras da Universidade do Porto, vol. 13, 211-226.

Poria, Y.; Reichel, A. \& Biran, A. (2006). Heritage site perceptions and motivations to visit. Journal of Travel Research, 318-326.

Poria, Y.; Richard, B. \& Airey, D. (2004). Links between tourists, heritage, and reasons for visiting heritage sites. Journal of Travel Research, 20-28.

Presidência Conselho Ministros. (2011). Programa do XIX Governo Constitucional. Retrived from: http: / /www. portugal.gov.pt/media/130538/programa_gc19.pdf.

Presidência Conselho Ministros. (2015). Programa do XXI Governo Constitucional. Retrived from: http://www. portugal.gov.pt/media/18268168/programa-do-xxigoverno.pdf.

Rebelo, J. \& Brito, R. (2014). Estudo sobre o valor económico da ligação às redes da Unesco em Portugal. Lisboa: Comissão Nacional da Unesco.

Richards, G. (1996). Production and consumption of European cultural tourism. Annals of Tourism Research, vol. 23, Issue 2, 1996. 261-283.

Rocha, A. \& Monastirsky, L. (2008). A dialéctica entre o global e o local.Terr@Plural, 2(1), 145-154.

Russo, A. P. (2002). The "vicious circle" of tourism development in heritage cities. Annals of Tourism Research, vol. 29, $\mathrm{n}^{\circ} 1,165-182$

Salema, I. \& Canelas, L. (2015, março 10). Vassallo e Silva: 'Património é património, turismo é turismo. Os nossos objectivos não são comuns'. Jornal Público. Retrieved from http://www.publico.pt/culturaipsilon/noticia/ nuno-vassallo-e-silva-turismo-e-turismo-patrimonioe-patrimonio-os-nossos-objectivos-nao-saocomuns- 1688566 .

Santos, N. (2013). Coimbra: a organização da cidade e do Centro Histórico Urbano. In J. A. Rio Fernandes \& M. Sposito (coord), A Nova Vida do Velho Centro nas cidades portuguesas e brasileiras (pp. 189-209). Porto: Universidade do Porto-CEGOT.

Santos, N. (2014). Turismo, gestão e território. Caderno Virtual de Turismo, vol. 14, supl. 1, Edição 
especial:Hospitalidade e políticas públicas em turismo, 66-86.

Tuan, Y (1970). Space and place: humanistic perspective. In J. Agnew, D. Livingstone \& A. Rogers (ed.), Human Geography (pp. 444-457). Oxford: Blackwell.

Tuan, Y. (1974). Space and place: humanistic perspective. Progress in Human Geography, 6, 233-246.

UNESCO (2013). Decisions adopted by the World Heritage Committee at its 37th Session (Phnom Penh, 2013). Retrieved from: http://whc.unesco.org/archive/2013/ whc13-37com-20-en.pdf.

Vecco, M. (2010). A definition of cultural heritage, Journal of Cultural Heritage, 11, 321-324.
Vinuesa, M. (2004). Turismo e desenvolvimento nas cidade históricas ibero-americanas: desafios e oportunidades. In A. P. Portuguez (coord), Turismo, memória e patrimônio cultural (pp. 33-50). São Paulo: Roca.

Worthing, D. \& Bond, S. (2008). Managing built heritage. The role of cultural Significance. Oxford: John Wiley and Sons.

Texto recebido em/Text submitted on: 06/04/2016 Texto aprovado em/Text approved on: 29/07/2016 